ELORE (ISSN 1456-3010), vol. 17 - 1/2010.

Julkaisija: Suomen Kansantietouden Tutkijain Seura ry. [http://www.elore.fi/arkisto/1_10/kolumni_lofstrom_1_10.pdf]

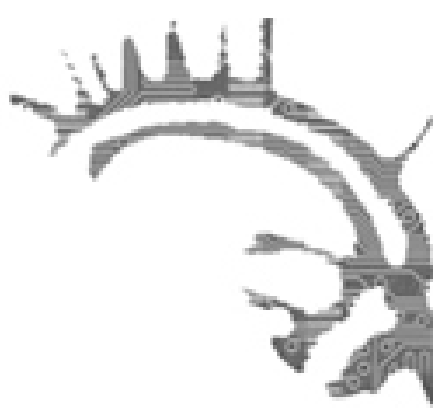

\title{
KOLUMNI
}

\section{Aistit, MUistot JA NEUROANTROPOLOGIA}

\section{$\underline{\text { Jan Löfström }}$}

Paljastan nyt erään erikoisuuteni: nuuhkin usein kirjoista niiden tuoksua. Kirjoilla on erilaiset tuoksunsa, jotka syntyvät monista eri tekijöistä: painomusteesta, paperista, selän liimasta, kannen materiaalista sekä joskus myös satunnaisista tekijöistä, kuten kirjan säilytysolosuhteista. Hartvig Frischin Euroopan kulttuuribistoria I-IV (1962-1963) on tietyn kirjatuoksun tyylipuhdas edustaja, kun taas Länder och folk i ord och bil (1937) edustaa toista hajutyyppiä, samaa johon kuuluu Mannerheimin Muistelmat I-II (1951), joskin viimeksi mainitun bukee on lapsuudenkotini kappaleessa paljon kevyempi ja lyyrisempi kuin Länder och folkin. Uusissa kotimaisissa taskukirjoissa tuoksu on verraten neutraali, sen sijaan englanninkielisissä pokkareissa, niin tieto- kuin kaunokirjallisissa teoksissa, lehahtaa nenään kiillottamattoman paperin rouhea tuoksu. Samanlaisen voi aistia $A k u$ Ankka -taskukirjoissa, mutta niissä sitä höystää painoväreistä syntyvä notkea aromi.

Periaatteessa kirjahyllyni voisikin yrittää järjestää kirjojen tuoksun mukaan, samaan tapaan kuin puutarhojen istutukset eurooppalaisissa hoveissakin saatettiin suunnitella, ennen kuin visuaalista vaikutelmaa korostavat uudet arvostukset 1600-luvulta lähtien alkoivat kiinnittää huomion kukkien muotoon, väriin ja kokoon niiden tuoksun sijasta - prosessi joka huipentui itse asiassa 1800-luvun lopulla (ks. Classen 1993, 15-36). En ole kuitenkaan toistaiseksi ryhtynyt tuollaiseen tuoksuperustaiseen ryhmittelyyn, enkä myöskään ole liukunut niin syvälle olfaktorisen mässäilyn tiellä, että hankkisin painoteoksia hyllyyni niiden tuoksun ansiosta. Erään kirjan tosin olen sieltä poistanut nimenomaan sen takia, että se lemusi niin pahasti: aikoinaan Englannissa 75 pencellä käytettyjen kirjojen laatikosta ostamani taskukirjaeditio Edmund Wilsonin sosialismin historian klassikkoteoksesta To the Finland station (1940) osoittautui lähitarkastelussa - siis lähihaistelussa - myöhemmin niin epämiellyttävän hajuiseksi (hometta?), että epäilin sen infektoivan vierustoverinsa kirjahyllyssä ja laitoin sen paperinkeräykseen.

Kirjatuoksujen viehätys ei kuitenkaan ole tuoksussa sinänsä, vaikka se toki on 
usein miellyttävä itsessäänkin. Asian viehätys piilee siinä, että mieleeni on kertynyt ajan myötä eräänlainen kirjatuoksujen muistopankki, jossa tuoksut assosioituvat paitsi kirjoihin esineinä myös erilaisiin, yleensä myönteisiin menneisiin kokemuksiin ja tilanteisiin, joissa tietty kirja - siis tietyntuoksuinen kirja - on ollut läsnä. Tällainen mieleni sopukoissa syntyvä assosiaatioketju voi sisältää esimerkiksi kirjan Mitä bän tekee? (1972, kuvitettu tietoteos nuorille erilaisista ammateista), sen tuoksun sekä välähdyksenomaisen muistuman, jossa kouluikäinen minä ajaa pyörällä heinäkuisen myöhäisiltapäivän auringossa ja tuulen kohinassa Pernajan kunnankirjastosta kotiin kirjapino repussa iloisena siitä, että kesälomaa on edessä vielä viikkokausia.

Tuoksujen merkitys muistamisen helpottajana ja muistojen herättäjänä on toki tuttua anekdootinomaisista ja omaelämäkerrallisista yhteyksistä, kuuluisana esimerkkinä Marcel Proustin romaani Kadonnutta aikaa etsimässä, ja laboratoriokokeista, mutta asia on todennettu myös asetelmaltaan arkisemmassa psykologisessa tutkimuksessa. John Aggleton ja Louise Waskett tekivät taannoin tutkimuksen, miten tuoksuvihjeet parantavat kykyä muistaa, mitä tietyntuoksuisessa ympäristössä on aiemmin nähty ja opittu (Aggleton \& Waskett 1999). Heillä oli koehenkilöinä 45 henkilöä, jotka olivat käyneet Yorkissa sijaitsevassa viikinkikautta rekonstruoivassa Jorvik Viking Centre -näyttelyssä. Näyttelyssä liikutaan eräänlaisen "aikavaunun" kyydissä tiettyä reittiä, ja matkan varrella on "historiallisia" tuoksuja tietyissä kohdin. Koehenkilöiden vierailut Jorvikissa olivat tapahtuneet melko kauan, keskimäärin 6-7 vuotta ennen Aggletonin ja Waskettin koetta.

Koehenkilöt saivat täyttää näyttelyn sisältöä koskevan "kokeen", kysymyslomakkeen kerran ja lyhyen ajan jälkeen toisen kerran. Heidät oli jaettu kolmeen ryhmään, joista yksi täytti lomakkeen ilman apuneuvoja. Yksi ryhmä sai lomakkeen lisäksi ampulleja, joissa ensimmäisellä kerralla oli Jorvikin tuoksuja ja lomakkeen toisella täyttökerralla muita tuoksuja, ja koehenkilöitä kehotettiin haistelemaan ampullien tuoksuja mielensä mukaan lomaketta täyttäessään. Kolmas ryhmä sai myös tuoksuampullit, mutta ensin kontrollituoksut ja toisella kertaa Jorvikin tuoksut. Tutkimuksen keskeinen tulos oli, että viimeksi mainitun ryhmän koetulos parani dramaattisesti, ja johtopäätös oli, että tuoksut siis voivat myös laboratorion ulkopuolisissa todenmukaisissa oloissa toimia tehokkaina mieleenpalauttamisen vihjeinä pitkänkin ajan kuluttua. (Herää kysymys, kannattaisiko ainakin historiallisia teemoja tutkivien etnologien jatkossa varustautua informanttien haastatteluun ottamalla mukaan aina sopivasti valittu tuoksuampullien kokoelma.)

Tämä tuoksujen ja tuoksuaistimusten yhteys yhtäältä muistiin, ja tarkemmin sanoen nimenomaan pitkäkestoiseen muistiin, sekä toisaalta tunteisiin on asia, joka selvästi kiehtoo ja kiinnostaa ihmisiä ja josta heillä on usein myös omakohtaista sanottavaa. Pääsin havaitsemaan tämän kirjoitettuani 1990-luvulla professori Bo Lönnqvistin $A r$ kielämän historiaa -projektin yhteydessä pari pientä tekstiä tuoksumuistoista ja tuoksujen historiallisesta antropologiasta (Löfström 2000a, Löfström 2000b). Nuo artikkelit poikivat lyhyessä ajassa useita lehti- ja jokusen radiohaastattelunkin, ja haastattelupyyntöjä tipahteli tasaiseen tahtiin vielä vuosia jälkeenpäin. (Itse asiassa viimeisin yhteydenotto asian tiimoilta on tullut Hämeen Sanomista syksyllä 2009.) Haastatteluissa oli yleensä kolme toistuvaa puheenaihetta: Miksi tuoksut herättävät usein voimakkaita muistoja? 
Onko yleismaailmallisesti hyvänä tai pahana pidettyjä tuoksuja? Miksi tuoksuista ei puhuta nykyään enempää, vaikka aihe on tavattoman kiinnostava?

Nuo kysymykset avautuvat oikeastaan antropologis-etnologisen aistien tutkimuksen laajemmiksi kysymyksiksi: Millainen paikka aistimuksilla on persoonamme ja oman muistoista rakentuvan minämme rakentumisessa? Millaisia merkityksiä aistimuksiin (esim. tiettyihin tuoksuihin) liitetään ja vastaavasti mitä aistimuksia assosioidaan eri asioihin (esim. mikä on "Suomen" väri tai "syksyn" ääni tai miltä "koulu" tuoksuu)? Mihin arvo- tai tärkeysjärjestykseen aistit asettuvat eri kulttuureissa, ja miten niiden keskinäinen suhde nähdään? Kuinka monta aistia ylipäänsä katsotaan olevan olevan olemassa?

Tuoksuihin ja hajuaistiin suhtautumisen historiaa koskevat haastattelukysymykset tuntuivat minusta aikanaan helpoimmilta vastata. Alain Corbinia lukeneena saatoin tarjota haastattelijalle tulkintaa, että modernissa kulttuurissa hajua koskevat asiat ovat olleet kiusallinen ja epähieno puheenaihe. Corbinhan esitti, että tuoksukielteisyys ja hajuttomuus oli nousevan porvariston symbolinen ase taistelussa yhteiskunnallisesta valta-asemasta $1700-l u v u l t a$ alkaen. Hajupolitiikallaan porvaristo vahvisti mielikuvaa kurinalaisuudestaan ja puhtaudestaan; vastapuolina katsottiin olevan parfyymeissä ja tuoksuvoiteissa piehtaroiva turmeltunut aristokratia sekä lialta haiseva köyhäläisten alaluokka. (Corbin 1982.) Porvarillis-keskiluokkaisen tuoksuregiimin myötä hajuaisti joutui kulttuurisesti sivuraiteelle. Mutta mitä myöhäismodernin länsimaisen kulttuurin aistihierarkiassa on mahdollisesti tapahtumassa ja miksi hajuaisti näyttää alkaneen taas saada arvostusta osakseen? Eräs esimerkki: 6.11.2009 Helsingin Sanomat uutisoi japanilaisen kodon, "tuoksujen tien" eli rituaalis-esteettisen tuoksujen harrastamisen saapuneen jo Suomeenkin. Tähän asiaan olisi kiinnostavaa saada antropologeilta ja etnologeilta punnittu analyysi ja tulkinta.

Aistimusten erilaisista merkityksistä ja arvostuksista tiedetään jo paljon historiallisantropologisen tutkimuksen ansiosta (esim. monipuolisuudessaan inspiroiva Classen, Howes \& Synnott 1994). Se on yleisinhimillisen tiedon ja ymmärryksen tavoittelun kannalta arvokasta tutkimusta itsessään, mutta tiedon käyttöarvoa ja sovellettavuutta peräänkuuluttaville virkamiehille pitäisi kaiketi puhua jostakin konkreettisemmasta "lisäarvosta". Voitaisiinko heille esittää, että kulttuurisen moninaisuuden kasvaessa suomalaisessakin yhteiskunnassa ihmisten peruskokemuksiin ja niiden variaatioon pureutuva tutkimus kuten aistihierarkioiden ja "aistimisprofilien" (Howes 1991b) antropologis-etnologinen tutkimus voisi edistää sujuvaa yhteiseloa eri kulttuurien edustajien kesken? Se kuulostaa sietämättömän välineelliseltä ja kulttuurista toiseutta liioittelevalta ja banalisoivalta, mutta jospa sillä saisi rahoitusta...

Edellä sanotusta löytyy ironian takaa vakavasti otettava ydin, jonka David Howes esitti jo noin 20 vuotta sitten: tutkiessamme erilaisia ja "meille" toisenlaisia tapoja aistia maailmaa saamme ehkä samalla innoitusta yrittää tavoitella itsellemme uusia tapoja olla suhteessa maailmaan (Howes 1991a). Kyse ei tällöin ole vain siitä, että näemme (modernin länsimaisen kulttuurin keskeinen aistihavainto!), miten tiettyjä aistimuksia saatetaan merkityksellistää eri tavoin (mikä on hyvä, mikä paha tuoksu jne.) ja miten aistimuksia sen mukaisesti pyritään tuottamaan ja säätelemään tietyn päämäärän suuntaisesti (mm. oman kehon tuoksun osalta; ks. Low 2007). On myös 
tärkeä oppia huomaamaan se mahdollisuus, että jokin asia tai esine saatetaan aistia toisten kvaliteettiensa kautta, kuin olemme itse tottuneet. Nadia Seremetakis kysyy retorisesti: "Kun tulkitsemme monin aistein lähestyttävissä olevia esineitä, esimerkiksi vaatetta, missä määrin tekstin lukemisen metafora vinouttaa tulkintaamme vaientamalla tavat, joilla [kyseisessä] kulttuurissa panostetaan aistimuksïn ja vastaanotetaan nïtä [...] Millä tavalla ibmiset olivat kosketuksissa vaatteeseen, ja mibin he sen kautta olivat kosketuksissa?" (Seremetakis 1996, 134)

Eräänlainen kulttuurikonstruktionistinen näkökulma aisteihin ja aistimuksiin onkin hedelmällinen, kun haluamme vastata aiemmin mainittuihin kysymyksiin aistimusten kulttuurisista merkityksistä ja eri kulttuurien mahdollisista erilaisista aistiprofiileista ja aistiregiimeistä. Mutta entä kysymys, millä tavoin aistimukset ovat rakentamassa persoonaamme ja miksi esimerkiksi tuoksut herättävät usein voimakkaita muistoja? Niihin vastaaminen haastatteluissa oli minulle vaikeaa, sillä se edellyttäisi laajempia psykologian ja neurofysiologian tietoja. Aisteihin ja yleensäkin hermojärjestelmään liittyvä tutkimus on edennyt jättiaskelin viime vuosina. Onkin kuvaavaa, että vuonna 2004 lääketieteen ja fysiologian Nobel-palkinto annettiin Richard Axelille ja Linda Buckille nimenomaan hajuaistin neurofysiologiaa koskevista tutkimuksista.

Biologian, lääketieteen ja fysiologian alan tutkimuksen tuntemus ei ole perinteisesti kuulunut antropologien ja etnologien (kuten myöskään yhteiskuntatieteilijöiden tai historiantutkijoiden) ydinosaamiseen. Norbert Elias - edelleen ehkä jossain määrin aliarvostettu suurten sosiologis-antropologisten kysymysten tutkija - opiskeli uransa alussa myös lääketiedettä, ja hänen kerrotaan myöhemmin kysyneen retorisesti, miten yhteiskuntatieteilijät voivat muodostaa ihmisen toiminnasta hyvän kuvan, jos he eivät ymmärrä itse organismia, ihmisen fysiologiaa ja anatomiaa (Mennell 1989, 7). On siis ehkä aika ryhtyä voimaperäisesti kehittämään neuroantropologiaa [http:// neuroanthropology.net], joka yhdistäisi antropologian, aivotutkimuksen ja vaikkapa filosofian ja sosiologiankin näkökulmia tutkiessaan ihmistä aistimellisena olentona. Se on kohtalaisen suuri haaste, mutta eivät antropologit ja etnologit kaiketi ole ennenkään haasteita pelänneet.

\section{KirJallisuUs}

AGGLETON, JOHN \& WASKETT, LOUISE 1999: The ability of odours to serve as state-dependent cues for real-world memories: Can Viking smells aid the recall of Viking experiences? British Journal of Psychology, 90:1, 1-7.

CLASSEN, CONSTANCE 1993: Worlds of sense: Exploring the senses in history and across cultures. London: Routledge.

CLASSEN, CONSTANCE \& HOWES, DAVID \& SYNNOT'T, ANTHONY $1994:$ Aroma. The cultural history of smell. London: Routledge.

CORBIN, ALAIN 1982: Le miasme et la jonquille. L'odorat et l'imaginaire social XVIIIeXIXe siècle). Paris: Aubier Montaigne.

HOWES, DAVID 1991 a: Introduction. - David Howes (toim.), The varieties of sensory experience: A sourcebook in the anthropology of the senses. Toronto: University of Toronto 
Jan Löfström: Aistit, muistot ja neuroantropologia

Press.

HOWES, DAVID 1991b: Sensorial anthropology. Teoksessa David Howes (toim.), The varieties of sensory experience: $A$ sourcebook in the anthropology of the senses. Toronto: University of Toronto Press.

LOW, KELVIN 2007: Presenting the self, the social body, and the olfactory: Managing smells in everyday life experiences. Sociological Perspectives, 49:4, 607-631.

LÖFSTRÖM, JAN 2000a: Lapsuuden hajut, vanhempien tuoksut. - Bo Lönnqvist (toim.), Arjen sä̈keet - aikakuvia arkielämään, sivilisaatioon ja kansankulttuurïn. Jyväskylän yliopiston etnologian laitoksen julkaisusarja Etnografia 3. Jyväskylä: Atena, 234-254.

LÖFSTRÖM, JAN 2000b: Aromeja aistien historiallisesta antropologiasta. Tutkimuskohteena hajut ja tuoksut. Historiallinen Aikakauskirja, 98:1, 15-22.

MENNELL, STEPHEN 1989: Norbert Elias: Civilization and the human self-image. Oxford: Oxford University Press.

NEUROANTROPOLOGY.NET [online] < http:// Neuroantropology.net > [19.1.2010.].

SEREMETAKIS, C. NADIA 1996: Implications. Teoksessa C. Nadia Seremetakis (toim.), The senses still: Perception and memory as material culture in modernity. Chicago: Chicago University Press.

Jan Löfström toimii historian didaktiikan yliopistonlehtorina Helsingin yliopiston opettajankoulutuslaitoksella ja historiallisen antropologian dosenttina Jyväskylän yliopistossa. 